\title{
Single phase heat transfer in minichannels
}

\author{
Jiri Hejcik ${ }^{1, a}$, Miroslav Jicha ${ }^{1}$ \\ ${ }^{1}$ Brno University of Technology, Faculty of Mechanical Engineering, Technicka 2896/2, 62669 Brno, Czech Republic
}

\begin{abstract}
The paper deals with the possibilities of measurement and evaluation of the heat transfer coefficient in circular minichannels. Evaluation procedure is demonstrated on real data and the results obtained are compared with the expected values of the heat transfer coefficient. Possible reasons for the difference are discussed.
\end{abstract}

\section{Introduction}

Minichannels heat exchangers are very popular especially in the areas of refrigeration and air conditioning in the last years. Not only do they offer increased heat transfer efficiency but also the possibility of reducing the amount of refrigerant charge and hence help fulfil the stringent environmental regulations.

Although the use of minichannel heat exchangers for a single-phase flow is not so common, they may offer some advantages. For example in the case of a shell and tube heat exchanger with a $30^{\circ}$ pipe arrangement, the replacement of a $5 \mathrm{~mm}$ outside diameter tube with a $2 \mathrm{~mm}$ one offers $30 \%$ increase in the heat transfer area, while maintaining the same pitch to diameter ratio of 1.5. But it will also reduce the flow cross-section by about $53 \%$, increasing the flow speed by $89 \%$ and thus increase in flow speed what potentially increases the pressure losses. On the other hand, based on the commonly used methods for the heat transfer calculation, the reduction of the hydraulic diameter causes an increase in the heat transfer coefficient, which is a positive effect in the case of heat exchangers. Hence a heat exchanger with $2 \mathrm{~mm}$ tubes requires approximately $30 \%$ of the original heat transfer surface to transfer the same heat load, thereby helps reduce the pressure losses. Even so, the pressure losses of the $2 \mathrm{~mm}$ tubes are higher than for the $5 \mathrm{~mm}$ ones with the same cross sectional area.

It is thus clear that the decision whether to use a minichannel or classical heat exchanger is quite challenging, making the need for sufficient theoretical bases.

\section{Experimental setup}

An experiment has been conducted to verify the applicability of the classical theory of heat transfer in the minichannel heat exchangers design and to determine the values of the heat transfer coefficient in a circular minichannel. The minichannel definition based on [1] is used in this work, so channels of the hydraulic diameter between 0.2 and $3 \mathrm{~mm}$ are considered as minichannels.

\subsection{Experimental test rig}

A minichannel test rig was built to prove the possibility of the conventional channel correlations application to tubular minichannels. The measuring principle is based on the calorimetric equation, which means that the temperatures and mass flow rate have to be measured to obtain the transferred heat rate and calculate the heat transfer coefficient. The schematic view of the rig is shown in figure 1.

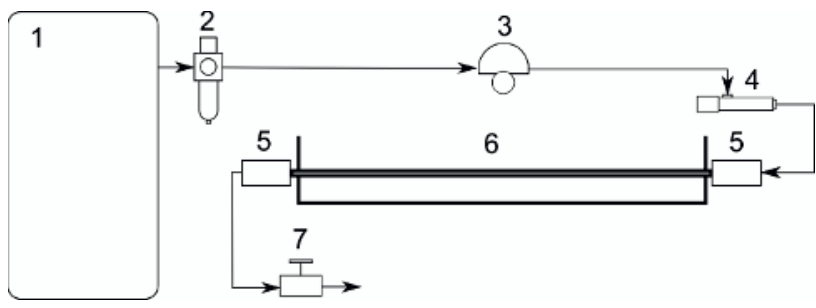

Figure 1. Test rig

Compressed air is used as a test medium. It is stored in an air-pressure tank (1) and it flows through the pressure reducing valve (2), Coriolis mass flow meter (3) and the electric heater (4) to the temperature header (5), where a temperature sensor is mounted. After that the air goes through a test section (6), where the tested channel is mounted and cooled by air, water or an ice-water mixture. The next temperature header is located after the test section to facilitate the temperature and pressure measurement. The compressed air mass flow regulation

\footnotetext{
a Corresponding author: hejcik@fme.vutbr.cz
} 
using a needle valve (7) is located behind this head and it terminating the compressed air flow path.

The precise NTC thermistors are used for the temperature measurement. There are six thermistors in each measuring head to obtain the air temperature at the inlet and outlet of the test section. Other thermistors are used to measure minichannel outside wall temperature and the ambient air temperature. Expected temperature measurement error is $\pm 0.5 \mathrm{~K}$.

Micro motion Coriolis flow meter is used for the air mass flow measurement, because it reaches very good measurement precision in the wide range of flow rates $(7-4500 \mathrm{~g} / \mathrm{h}$ in our test rig).

Commercially available tubes are usually used as a test channels in this test rig. They are inserted into the test section and joined to the temperature headers by compression fittings. Subsequently the three additional temperature sensors are glued on the minichannel surface to measure the wall temperature near the headers and in the middle of the minichannel. The test section is then exposed to the surrounding air or it is filled up with water or ice-water mixture so that the minichannel is fully submerged and the test rig is prepared for the measurement.

\subsection{Measurement process and data evaluation}

An aluminium tube with $2 \mathrm{~mm}$ internal diameter and $1 \mathrm{~mm}$ wall thickness was used as a tested minichannel. The tube length is $500 \mathrm{~mm}$ and its surface was exposed to the surrounding air, because it was planned to use obtained results for a ventilation unit heat exchanger sizing.

Measurements were performed for a range of Reynolds numbers 500 - 4000, which is expected to be a most suitable area for the minichannels heat exchangers.

The measurement procedure consists of a few steps, which were repeated for every measurement point (Reynolds number). First of all the required air pressure level and mass flow rate was pre-set by the pressurereducing valve and the needle valve. Next, the heater was turned on and the system heated up for a couple of minutes to reach the air inlet temperature about $50{ }^{\circ} \mathrm{C}$. After that the pressure level and mass flow rate was tuned up to the required value and the 30 - 90 minutes long stabilisation phase of measurement started. The experimental data were acquired during the 15 minutes of the following measurement stage. The original sampling frequency was $2 \mathrm{~Hz}$ but the data were averaged and stored every 10 seconds which means that 90 samples of measured values were obtained for each measurement point.

Data evaluation started by averaging the recorded values of the individual sensors, thereby obtaining the mean values during the measurement. Temperatures of the air inlet and outlet as well as the outside surface temperature of the minichannel were subsequently calculated as the mean values of appropriate temperature sensors.
Sutherland's formula and polynomial equations were used to calculate the dry air thermal and transport properties for the bulk temperature conditions.

Originally it was envisaged to use Wilson plot method for finding the appropriate coefficients of correlation equation, since this method does not require precise knowledge of the values of heat transfer coefficient on the outside surface of the examined channel. However the initial experiments showed that the results obtained with the help of the original Wilson plot method are not applicable and a new evaluation process was established, based on the procedure of the heat exchangers sizing [2].

This method comprises the following 8 calculation steps:

- Heat transfer rate $Q$

$$
Q=\dot{m} \cdot c_{p}\left(T_{\text {in }}-T_{\text {out }}\right)
$$

- Reynolds number Re

$$
R e=\frac{\dot{m} \cdot d}{\mu \cdot A_{c}}
$$

- Logarithmic mean temperature difference $\Delta T_{l n}$

$$
\Delta T_{\text {ln }}=\frac{\left(T_{\text {in }}-T_{\text {air }}\right)-\left(T_{\text {out }}-T_{\text {air }}\right)}{\ln \frac{T_{\text {in }}-T_{\text {air }}}{T_{\text {out }}-T_{\text {air }}}}
$$

- Total thermal resistance $R_{t o t}$

$$
R_{t o t}=\frac{\Delta T_{l n}}{Q}
$$

- Minichannel conductive thermal resistance $R_{k}$

$$
R_{k}=\frac{\ln \frac{D}{d}}{2 \cdot \pi \cdot k \cdot L}
$$

- Minichannel convective thermal resistance on the outer surface $R_{h_{-} \text {out }}$

$$
R_{h_{-} \text {out }}=\frac{1}{h_{\text {out }} \cdot \pi \cdot D \cdot L}
$$

- Minichannel convective thermal resistance on the internal surface $R_{h}$ in

$$
R_{h_{-} \text {in }}=R_{\text {tot }}-R_{h_{-} \text {out }}-R_{k}
$$

- Heat transfer coefficient in the minichannel $h_{\text {in }}$

$$
h_{\text {in }}=\frac{1}{R_{h_{-} \text {in }} \cdot \pi \cdot d \cdot L}
$$

The most problematic part of the calculation is to determine the heat transfer coefficient on the outer surface of the minichannel. In our case, we used the 
average of the two calculated values obtained from Morgan correlation for $10^{-2}<R a<10^{2}$ (9) and Churchill and Chu correlation (10), recommended by [3] to determine the natural convection heat transfer coefficient from a horizontal cylinder.

$$
\begin{gathered}
h_{\text {out }}=1.02 \cdot R a^{0.148} \cdot \frac{k_{\text {air }}}{D} \\
h_{\text {out }}=\left\{0.60+\frac{0.387 \cdot R a^{1 / 6}}{\left[1+(0.559 / P r)^{9 / 16}\right]^{8 / 27}}\right\}^{2} \frac{k_{\text {air }}}{D}
\end{gathered}
$$

Values of the heat transfer coefficient, obtained by this method, were compared with the heat transfer coefficients calculated from the constant Nusselt number for the fully developed laminar flow with constant wall temperature or with the values of the heat transfer coefficient obtained from correlation equation (11) which is the most popular for the Reynolds numbers between 2300 and 10000 [4].

$$
\begin{gathered}
h=\frac{(f / 2)\left(R e_{b}-1000\right) \cdot P r_{b}}{1+12.7(f / 2)^{1 / 2}\left(\operatorname{Pr}^{2 / 3}-1\right)} \cdot \frac{k_{b}}{d} \\
f=\left(1.58 \cdot \ln \left(\operatorname{Re}_{b}\right)-3.28\right)^{-2}
\end{gathered}
$$

\section{Results and discussion}

\subsection{Obtained results}

Mass flow rates and temperatures obtained from the measurement on the $2 \mathrm{~mm}$ internal diameter aluminium minichannel are listed in Table 1.

Table 1. Measured values for the $2 \mathrm{~mm}$ minichannel

\begin{tabular}{|c||c|c|c|c|c|c|}
\hline \multirow{2}{*}{$\begin{array}{c}\text { Meas. } \\
\text { point }\end{array}$} & $\dot{\boldsymbol{m}}$ & $\mathbf{T}_{\text {in }}$ & $\mathbf{T}_{\text {out }}$ & $\mathbf{T}_{\mathbf{w} \_ \text {in }}$ & $\mathbf{T}_{\mathbf{w} \_ \text {out }}$ & $\mathbf{T}_{\text {air }}$ \\
\hline \hline $\mathbf{1}$ & $1.49 \mathrm{Eg} / \mathbf{s}]$ & {$\left[{ }^{\circ} \mathbf{C}\right]$} & {$\left[{ }^{\circ} \mathbf{C}\right]$} & {$\left[{ }^{\circ} \mathbf{C}\right]$} & {$\left[{ }^{\circ} \mathbf{C}\right]$} & {$\left[{ }^{\circ} \mathbf{C}\right]$} \\
\hline $\mathbf{2}$ & $2.50 \mathrm{E}-05$ & 49.1 & 21.8 & 29.5 & 23.0 & 18.9 \\
\hline $\mathbf{3}$ & $3.21 \mathrm{E}-05$ & 54.4 & 28.1 & 47.5 & 31.9 & 19.1 \\
\hline $\mathbf{4}$ & $4.34 \mathrm{E}-05$ & 57.2 & 33.4 & 51.4 & 37.9 & 19.2 \\
\hline $\mathbf{5}$ & $5.90 \mathrm{E}-05$ & 58.2 & 37.8 & 52.6 & 39.6 & 19.4 \\
\hline $\mathbf{6}$ & $9.56 \mathrm{E}-05$ & 57.4 & 39.9 & 52.9 & 43.8 & 19.2 \\
\hline $\mathbf{7}$ & $1.19 \mathrm{E}-04$ & 56.7 & 41.3 & 52.5 & 44.7 & 19.2 \\
\hline
\end{tabular}

The values of the Reynolds number, heat transfer rate, logarithmic mean temperature difference and total thermal resistance were determined using equations $(1-4)$ and they are listed in Table 2.
Table 2. Calculated values

\begin{tabular}{|c||c|c|c|c|}
\hline \multirow{2}{*}{$\begin{array}{c}\text { Meas. } \\
\text { point }\end{array}$} & $\mathbf{R e}$ & $\mathbf{Q}$ & $\Delta \mathbf{T}_{\mathbf{l n}}$ & $\mathbf{R}_{\text {tot }}$ \\
\cline { 2 - 5 } & {$[-]$} & {$[\mathbf{W}]$} & {$[\mathbf{K}]$} & {$[\mathbf{K} / \mathbf{W}]$} \\
\hline $\mathbf{1}$ & 507.3 & 0.27 & 9.3 & 33.85 \\
\hline $\mathbf{2}$ & 841.5 & 0.64 & 14.7 & 22.94 \\
\hline $\mathbf{3}$ & 1069.4 & 0.85 & 19.2 & 22.62 \\
\hline $\mathbf{4}$ & 1430.0 & 1.04 & 24.1 & 23.26 \\
\hline $\mathbf{5}$ & 1932.5 & 1.21 & 27.4 & 22.65 \\
\hline $\mathbf{6}$ & 3126.2 & 1.68 & 28.6 & 16.99 \\
\hline $\mathbf{7}$ & 3883.7 & 1.84 & 29.2 & 15.80 \\
\hline
\end{tabular}

Thermal resistance of the minichannel wall, $R_{k}$ was the same in all cases and it equalled to $7.87 \cdot 10^{-4} \mathrm{~K} / \mathrm{W}$. The values of the thermal resistance and the calculated value of the heat transfer coefficient in minichannels are shown in Table 3. There are also values of "expected" heat transfer coefficient $h$, determined from the constant Nusselt number $N u=3.66$ in the case of the laminar flow $(R e<2300)$ or from the (11) for the turbulent flow. The last column in Table 3 shows the relative difference between the expected and measured values.

Table 3. Heat transfer coefficient

\begin{tabular}{|c|c||c|c|c|c|c|}
\hline \multirow{2}{*}{$\begin{array}{c}\text { Meas. } \\
\text { point }\end{array}$} & $\mathbf{R e}$ & $\mathbf{R}_{\mathbf{h}_{-} \text {out }}$ & $\mathbf{R}_{\mathbf{h}_{\_} \text {in }}$ & $\mathbf{h}_{\text {in }}$ & $\mathbf{h}$ & \multirow{2}{*}{ diff. } \\
\cline { 2 - 6 } & {$[-]$} & {$[\mathbf{K} / \mathbf{W}]$} & {$[\mathbf{K} / \mathbf{W}]$} & \multicolumn{2}{|c|}{$\left[\mathbf{W m}^{-2} \mathbf{K}^{-1}\right]$} & \\
\hline $\mathbf{1}$ & $\mathbf{5 0 7 . 3}$ & 17.32 & 16.53 & $\mathbf{1 9 . 3}$ & 48.5 & $-60.3 \%$ \\
\hline $\mathbf{2}$ & $\mathbf{8 4 1 . 5}$ & 15.32 & 7.62 & $\mathbf{4 1 . 8}$ & 49.4 & $-15.4 \%$ \\
\hline $\mathbf{3}$ & $\mathbf{1 0 6 9 . 4}$ & 14.55 & 8.07 & $\mathbf{3 9 . 4}$ & 49.9 & $-21.1 \%$ \\
\hline $\mathbf{4}$ & $\mathbf{1 4 3 0 . 0}$ & 13.99 & 9.27 & $\mathbf{3 4 . 3}$ & 50.5 & $-32.0 \%$ \\
\hline $\mathbf{5}$ & $\mathbf{1 9 3 2 . 5}$ & 13.86 & 8.79 & $\mathbf{3 6 . 2}$ & 50.9 & $-28.9 \%$ \\
\hline $\mathbf{6}$ & $\mathbf{3 1 2 6 . 2}$ & 13.63 & 3.36 & $\mathbf{9 4 . 7}$ & 146.0 & $-35.1 \%$ \\
\hline $\mathbf{7}$ & $\mathbf{3 8 8 3 . 7}$ & 13.61 & 2.20 & $\mathbf{1 4 5 . 0}$ & 182.9 & $-20.7 \%$ \\
\hline
\end{tabular}

\subsection{Discussion}

From Table 3 it is evident that the values of the heat transfer coefficient obtained by measurement are lower than the "expected" ones calculated from commonly used correlation equations. The difference between the expected and the measured value is in most cases greater than $20 \%$ which is higher than the normally considered maximum error for the heat transfer coefficient calculations. It would therefore seem that it is not possible to use conventional correlation equations for the minichannel heat transfer coefficients calculations as it is recommended in the [5].

On the other hand, it is necessary to account for a number of other factors that may influence the measurement results.

One of them is the measuring accuracy. Although the highly accurate low flow mass flow meter is used its measurement accuracy is limited and measurement 
uncertainty may exceed the measured value (in case of very small flows). The uncertainty of mass flow measurement was lower than $10 \%$ for the results presented in Table 1. Similar problems occur with the temperature measurement. Although the sensor itself is very accurate, it is not able to determine the temperature of the airflow with an accuracy better than $\pm 0.5 \mathrm{~K}$, so that the uncertainties of the temperature difference measurements are higher than 5\%.

Other problem of the published results seems to be the experimental arrangement. Because of the air is used as a cooling fluid and only a natural convection heat transfer is used to extract heat from the minichannel surface, the results are probably strongly influenced by a longitudinal conduction. This is evident from Table 1 where the values of the wall temperature close to the end of the minichannel $\left(T_{w_{-} \text {out }}\right)$ are greater than the fluid temperature at the end of test section $\left(T_{\text {out }}\right)$. This means that heat is transferred from the wall to the fluid instead of from the fluid to the surroundings. It looks like there is heat "recirculation" where the heat is transferred from the air to the wall at the beginning of the microchannel and it goes back to the fluid at the end of test section hence measured values of the heat transfer coefficient do not correspond to the actual values.

Another weak point can also be found in the evaluation procedures where the heat transfer rate extracted from the minichannel surface (determined from the measured surface temperature, air temperature and calculated average value of the heat transfer coefficient on the outside surface) is higher than the heat transfer rate from the flowing medium.

\section{Conclusions}

On the basis of experimental data, it would seem that the heat transfer coefficient inside the tubular minichannels is lower than expected according to the classical correlation equations. Detailed analysis of measured values, however, show that such a conclusion cannot be drawn, since the measured data show some discrepancies.

Although the described process of measurement and evaluation of the heat transfer coefficient inside the tubular minichannels was based on the logical assumption it does not work very well. The obtained results showed that the measurement of the heat transfer coefficient in minichannels requires more precise measurement techniques and experimental setup.

Revision of the data evaluation and measurement methodology was proposed based on the realized experiments. The main goals of the proposed changes are to minimize longitudal thermal conductivity and to increase measurement accuracy. The plans to reach these goals are to use a thin wall stainless steel minichanels, enhance the outside surface cooling and use differential temperature measurement instead of manipulating more values.

\section{Acknowledgement}

The authors would like to greatly acknowledge the financial support received from the Czech Science Foundation (under the project No. P101/11/P538), from the Faculty of Mechanical Engineering, Brno University of Technology (project No. FSI-S-11-6) and from the project NETME Centre (no. CZ.1.05/2.1.00/01.0002).

\section{References}

1. S.G. Kandlikar, Exp. Therm. and Fluid Sc.26, 389 (2002)

2. J. Hejcik, 32. Stretnutie katedier Mechaniky tekutín a Termomechaniky (Tatranská Lomnica, 2013)

3. F.P. Incropera et al., Fundamentals of heat and mass transfer (2007)

4. S. KAKAÇ, Heat exchangers: selection, rating, and thermal design (2002)

5. S.G. Kandlikar et al., Heat transfer and fluid flow in minichannels and microchannels (2006)

\section{Nomenclature}

$\begin{array}{cll}A c & {\left[\mathrm{~m}^{-2}\right]} & \text { Cross section area } \\ c & {\left[\mathrm{~J} \cdot \mathrm{kg}^{-1} \mathrm{~K}^{-1}\right]} & \text { Specific heat } \\ d & {[\mathrm{~m}]} & \text { Minichannels internal diameter } \\ D & {[\mathrm{~m}]} & \text { Minichannels external diameter } \\ h & {\left[\mathrm{~W} \cdot \mathrm{m}^{-2} \mathrm{~K}^{-1}\right]} & \text { Heat transfer coefficient } \\ k & {\left[\mathrm{~W} \cdot \mathrm{m}^{-1} \mathrm{~K}^{-1}\right]} & \text { Thermal conductivity } \\ L & {[\mathrm{~m}]} & \text { Minichannel length } \\ \dot{m} & {\left[\mathrm{~kg} \cdot \mathrm{s}^{-1}\right]} & \text { Mass flow rate } \\ N u & {[-]} & \text { Nusselt number } \\ P r & {[-]} & \text { Prandtl number } \\ Q & {[\mathrm{~W}]} & \text { Heat transfer rate } \\ R & {\left[\mathrm{~K} \cdot \mathrm{W}^{-1}\right]} & \text { Thermal resistance } \\ R a & {[-]} & \text { Rayleight number } \\ R e & {[-]} & \text { Reynolds number } \\ T & {[\mathrm{~K}]} & \text { Temperature } \\ \Delta T_{l n} & {[\mathrm{~K}]} & \text { Logarithmic mean temperature } \\ & & \text { difference } \\ \mu & {[\mathrm{Pa} \cdot \mathrm{s}]} & \text { Viscosity } \\ & & \end{array}$

